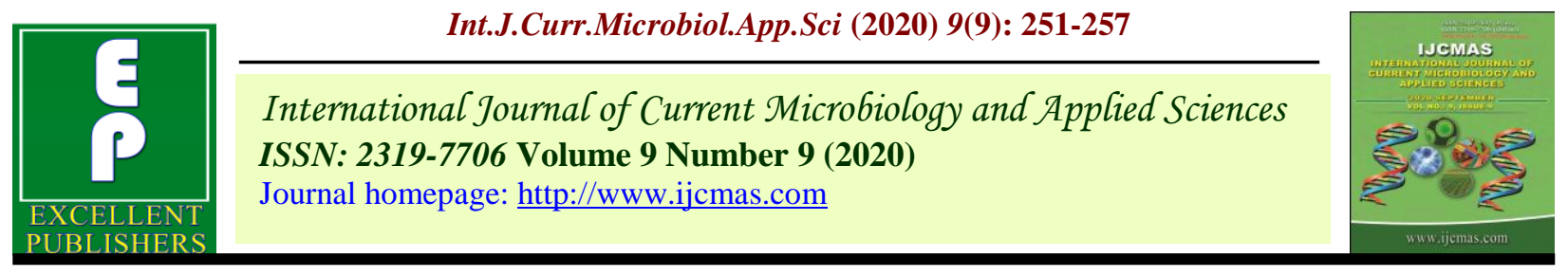

Review Article

https://doi.org/10.20546/ijcmas.2020.909.031

\title{
Radon: The Hidden Killer
}

\author{
Tirthankar Dalui* and Ankita Mondal
}

Department of Zoology, Barasat Govt. College, Kolkata-700126, India

*Corresponding author

\begin{abstract}
A B S T R A C T
\section{Keywords}

Radon, Radioactive, Lung cancer, MicroRNA, Genotoxicity

Article Info

Accepted: 04 August 2020 Available Online: 10 September 2020

Radon $(\mathrm{Rn})$ is a naturally occurring radioactive gas in rocks and soils. The long radioactive decay of uranium forms radon. Radon decays to form radioactive particles that may enter the body through inhalation. Daughter products of radon release high energy alpha particles associated with gamma rays when radon undergoes radioactive decay. It is the second most common cause of lung cancer after smoking. When inhaled with radon gas, high energy ionizing alpha particles are produced from the 222Rn decay. Some of these alpha particles will interfere with biological tissue in the lungs resulting in weakened of cell's DNA. Everyone is, to some extent, exposed to radon. Cracks in solid floors and under walls, gaps in suspended concrete and wooden floors and round pipe works and crack space, cavities in walls, building joints and small cracks or pores in hollow walls, can lead to radon entry into the building. The genotoxicity of radon gas is addressed primarily to bronchial epithelial and lung parenchyma. Radon comes into the body via the respiratory system. Therefore, the main target of its toxic eff ects is lung cells, where further decay occurs by emitting ionizing radiation, causing oxidative damage to DNA, proteins, and lipids. Accumulation of such damages in a cell, contribute to malignant transformation. The epigenetic basis of lung cancer is related primarily to changes in the profile of microRNA (miRNA). Lung damage associated with radon exposure was attributed to disturbances in miRNA and subsequent protein expression.
\end{abstract}

\section{Introduction}

Radon ( $\mathrm{Rn})$ is a naturally occurring radioactive gas in rocks and soils. The long radioactive decay of uranium forms radon. Uranium is found in the soils and the rock in small quantities. Radon decays to form radioactive particles that may enter the body through inhalation. The heaviest of all noble gasses is radon. Because it is the sole significant contributor to the general population's ionizing radiation dose, it is more soluble in organic fluids than water. It has gained the most attention in the last four decades among all the noble gasses. Daughter products of radon release high energy alpha particles associated with gamma rays when radon undergoes radioactive decay. It is estimated that about half of the total natural radiation exposure for human beings comes from radon (UNSCEAR, 2000). It is the second most common cause after smoking for lung cancer and is regarded as a human carcinogen. Because of the strong combined 
effect of smoking and radon radiation, most cases of radon-induced lung cancer have occurred among smokers. Radon is the number one cause of lung cancer among nonsmokers, according to the Environmental Protection Agency (EPA) (WHO, 2009). When inhaled with radon gas, high energy ionizing alpha particles are produced from the 222Rn decay. Some each of these alpha particles will interfere with biological tissue in the lungs and significantly weakened a cell's DNA. Lung cancer has been listed as the leading cause of death worldwide by the World Health Organization. Currently, there are 8.2 million deaths annually; it was apparent. By 2030 the number of deaths from lung cancer is estimated to rise to 10 million per annum. Like other cancer types, lung cancer is a multifaceted illness. Smoking by cigarettes is the leading risk factor, but the increase in lung cancer, mainly in radon and their progeny, cause other factors.

\section{Radon emission and migration}

This chemically inert radioactive gas naturally occurs as an indirect uranium decay product. The central members of each natural radioactive chain are the radon isotopes such as $222 \mathrm{Rn}, 220 \mathrm{Rn}$, and $219 \mathrm{Rn}$.It can be found in diverse concentrations of soil, water and air.It has unstable isotopes that disintegrate into polonium (218Po), lead $(214 \mathrm{~Pb})$, and bismuth isotopes. The half-life of radon can range from a minute $\left({ }^{220} \mathrm{Rn}\right)$ to several days $\left({ }^{222} \mathrm{Rn}\right)$ and is accompanied by the release of alpha particles (Bersimbaev et al., 2020). Radon permeates the surface of the planet by fractures and accumulates in the lower atmosphere. An increased concentration of radon in air is seen in regions rich in deposits of uranium, as well as near uranium mines. Nearly everywhere, natural uranium is present at different levels. Everyone is, to some extent, exposed to radon. In soils, typically 20 to 40 percent of newly generated radon atoms, in clays up to 70 percent, are released into pores where it is mixed with pores filled by gasses or water. The diffusion or the flow of radon into carrier fluids, such as soil air or water, can transmit radon from the pore area. The rate of release of radon from rocks and soils is greatly controlled by their uranium and radium concentrations and grain size and the types of minerals in which the uranium occurs (British Geological Survey, 2012). Cracks in solid floors and under walls, gaps in suspended concrete and wooden floors and round pipe works and crack space, cavities in walls, building joints and small cracks or pores in hollow walls, can lead to radon entry into the building. In basements and ground floor spaces that are connected with soil or rock, the concentrations of radon are significantly higher. The indoor radon level is also supported by air released by water during showering and other domestic work. This generally contributes almost nothing to the overall radon level. Pressure-induced flow through cracks and holes in the floor is the dominant mechanism of radon entry. Slightly negative pressure differences between the indoor and outdoor environments attract polluted air into the building, primarily through the floor, by wind outside and heating inside of the building. Poor ventilation may increase radon concentrations, but it is not the fundamental cause of high indoor radon levels (Appleton, 2013).

\section{Radon Exposure and Lung Cancer}

The relationship between radon and lung cancer is well established by epidemiologic studies suggesting that $70 \%$ of lung cancer deaths among uranium miners are attributable to radon exposure. Uranium miners have remarkably considerable genomic damage in blood lymphocytes as well as a high risk of developing lung cancer (Bersimbaev et al., 2020; Kreuzer et al., 2015). The primary radon source from indoor air (>95\%) is only 
a small part of other sources, mostly water (1\%).Radon is mostly extracted from polluted water by running water, including washing, shaving, showering and hot tub swimming. By drinking, only 0.1 percent of this amount enters the body. The study showed that mortality from lung cancer is directly linked to locations with high radon levels. As an alpha emitter, radon directly causes genotoxic and clastogenic harm at the absorption site. The genotoxicity of radon gas is addressed primarily to bronchial epithelial and lung parenchyma. Eff ects on distant organs could only be related to the absorption of nanoparticles able to cross the capillary endothelium in the lung (Pei et al., 2017). When subjected to radon, lung tissue became severely injured, as shown by pathological diagnosis and immuno-histochemical examination. Accordingly, radon triggered pathogenic chain reaction incident is genotoxic injury, apoptosis, and inflammation. Radon comes into the body via the respiratory system. Therefore, the main target of its toxic effects is lung cells, where further decay occurs by emitting ionizing radiation, causing oxidative damage to DNA, proteins, and lipids (Reisz et al., 2014). Accumulation of such damages in a cell, contribute to malignant transformation (Sosa et al., 2013). Growing numbers of retrospective studies indicate that radon has carcinogenic potential. Damage caused by the radon leads to malignancy. Likewise, cumulative exposure to radon may contribute to increased tumor mutation burden in non smoker patients with lung cancer, and the mutagenesis has been associated with malfunctioning repair of the DNA.Radoninducedlungcancersusceptibilityisrelatedtogen esinvolving DNA dealkylation (Rosenberger et al., 2018). Genetic factors are also considerable contributors to lung cancer pathogenesis. The first-degree family members of lung cancer patients are at an increased risk even after smoking adjustment.
The carcinogenic effect is caused by the accumulation of genetic polymorphisms (Bulgakova et al., 2019), chromosomal abnormalities and mutations in tumor suppressor genes (Bersimbaev et al., 2020; Kanwal et al., 2017). An increased risk of chromosome aberration in radon-exposed children was also associated with polymorphisms of DNA repair genes (APE, XRCC1, OGG1, ADPRT, XpC, XpD, XpG, Lig4, and NBS1). The function of genetic markers in developing lung cancer in non smokers have been demonstrated in several studies.

\section{MicroRNA in Lung Cancer}

miRNA may be proposed as a new diagnostic too lincan certo identify high-risk subjects and early cancer stages by liquid biopsy (Izzotti et al., 2016). The epigenetic basis of lung cancer is related primarily to changes in the profile of microRNA (miRNA). miRNAs are a class of small single-stranded nonprotein-coding RNAs that play important roles in diff erent cellular processes including cell development and proliferation, diff erentiation, growth control, and apoptosis (Nair et al., 2013). miRNAs are typically 18 25 nucleotides and are commonly retained in nature and are incredibly tissue-specific. miRNAs are involved in the regulation of target genes at the post-transcriptional level, miRNAs can covalently bind to complementary sequences of the 30UTR region of the mRNA and inhibit translation (Peng and Croce, 2016). Recent data indicated that miRNAs are engaged in the regulation of cellular processes induced by radiation and consequently can potentially be used as biomarkers to assess the degree of exposure to radiation in humans (Chauldhry, 2014). MicroRNAs are massively dysregulated during lung carcinogenesis induced by cigarette smoke (Bersimbaev et al., 2020; Izzotti et al., 2009) and by other 
environmental airborne lung carcinogens (Izzotti and Pulliero, 2014). In humans, the expression profile of several miRNAs, in bronchial epithelium BEAS2B cells, have been altered upon exposure to radon (Cui et al., 2013).is altered by radon with up regulation and down regulation of some specific microRNA in the human bronchial cellular epithelium. All types of changes affect the cell cycle, oxidative stress, inflammation, induction of oncogene, methylation of DNA and malignancy. miR-29 addresses methyl DNA inhibition methyl transfers from $\mathrm{CpG}$ sites. The radon exposure in the lung causes massive microRNA dysregulation. In the event of long-term radon exposure, microRNA modifications lead to the development of cancer.

Fig.1 Events leading from irradiation of cells by alpha particles to cancer

(Bersimbaev et al., 2020)

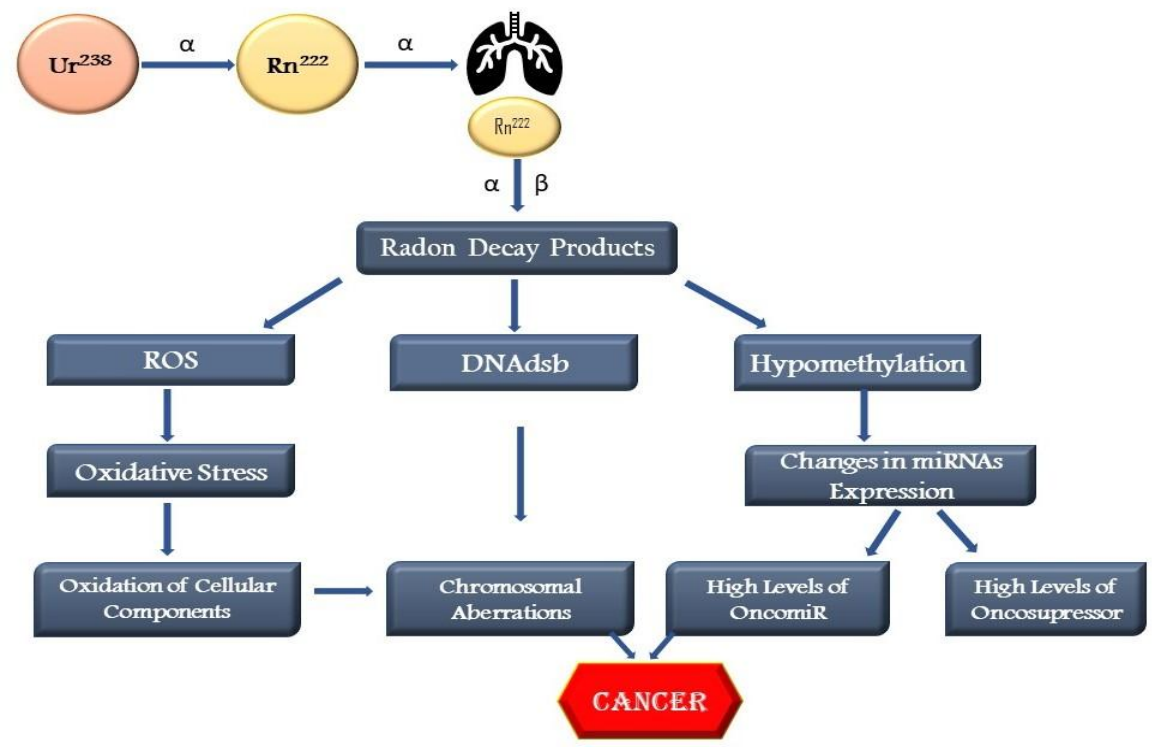

\section{Epigenetic factor in Radon-Induced Lung Cancer}

MiRNA are involved in the regulation of radiation-induced cellular processes and can theoretically be used as biomarkers for assessing the level of radiation exposure in humans. Collectively, 1000 dysregulated noncoding RNA (ncRNA) and miRNA transcripts were found due to radon exposure, and these long non-coding RNA (lncRNA) play an essential role in lung damage by radon exposure (Bersimbaev et al., 2020; Nie et al., 2019).In regulating different lung cancer target genes, miRNAs play an essential role. Researchers have shown that the terms miR-
$34 \mathrm{a}$ and increased cellular apoptosis were upregulated by chronic radon exposure in a time related way. Chronic exposure to radon produced up-regulation of the miR-34a gene, which subsequently enhanced apoptosis in BEAS-2B cells (Bersimbaev et al., 2020; Wang et al., 2018). Through interacting with RNAs, protein and DNA, ncRNAs exercise biological function. Lung damage associated with radon exposure was attributed to disturbances in miRNA and protein expression. Besides, alterations to miRNA-7, miRNA-17, and miRNA-214 have been shown to play a pathogenic role in radonrelated lung cancer. Fig. 1 describes the sequence of events arising from cell 
irradiation by alpha particles to cancer. A sequence of events leading to cancer through cell irradiation by alpha and beta particles. Diverse cell damage was caused by ionizing radiation like double-strand DNA breaks (DNAdsb), reactive oxygen species (ROS) formation, and $\mathrm{CpG}$ sites hypomethylation. As a consequence of oxidative stress, increased ROS contributes to the oxidation of the cellular components. Double-stranded DNA breaks have created that lead to chromosomal rearrangements. miRNA gene promoters hypomethylation is leading to a shift in their profile. All of these cell changes are harmful factors that can lead to cell malignancy and cancer. Exposure to high doses of radon leads to lower levels of miR194. In lung oncology, miR-194 overexpression prevents cancer cell metastasis.MiR-194 targets BMP1 and p27 kip1. The downgrade of BMP1 removes TGF $\beta$ activity; in effect, the functions of the MMP2 and MMP9 are reduced. In addition, miRNA-194-induced suppression of p27 kip1 activates the RhoA signaling pathway, which enhanced the development of actin stress fibers and impaired cancer cell migration (Bersimbaev et al., 2020; Wu et al., 2013). MiR-19b-3p has recently been shown to be related to a risk of pulmonary neoplasm.MiR$19 b-3 p$ was significantly higher than in the healthy control group in blood plasma for patients with lung cancer. Differences in the expression of miR-19b-3p have been statistically significant in cancer patients who are exposed to prolonged radon exposure and in low-radon areas. Therefore miR-19b-3p is not suited as the radon exposure genetic marker.

In conclusion the chance of developing lung cancer refers to the average annual radon level in the household, and how much time one spends there. The lengthier the radon exposure, the higher the risk, especially in the case of young children and smokers. The difference in air pressure, our house is working like a giant vortex, pulling radon gas into the foundation or basement floor through any crack. Radon exposure causes gene mutation \& chromosome aberrations in miners. So, it is suggested to test our home with a radon testing kit. If the result is higher than $4 \mathrm{pCi} / \mathrm{L}$, i.e., the level of action, we must contact a licensed professional, and they may seal cracks or install a ventilation system so that radon is not trapped inside. There are two general forms to monitor the radon; one is short-term testing (2-90 days at home) \& long-term testing ( $>90$ days in-home). Radon is one of the simplest to address all environmental concerns. Sealing holes and gaps in basement floors, foundation walls, openings around pipes, etc. are all it takes. In other situations, a unique suction system known as the sub-slab de-pressurization system may need to be mounted, which draws air from below the basement floor and exhausts it to the outside or installs a radon vent fan which draws the radon gas and releases it into the outside air. Whatever the methods used, it can almost always be easily reduced to a high radon level. There are no commonly available medical tests for determining whether you were exposed to radon. miRNA expression changes occur after radon exposure. Mostly in the case of long term exposure to radon, changes in miRNA can lead to growth in lung cancer.

\section{References}

Appleton J.D., (2013). Radon in Air and Water. Alloway B.J., Essentials of Medical Geology, 239-277.

Bersimbaev R., Pulliero A., Bulgakova O., Asia K., Aripova A. and Izzotti A., (2020). Radon Biomonitoring and MicroRNA in Lung Cancer. International Journal of Molecular Science, 21(6): 2154-2171.

British Geological Survey, (2012). Naturally 
occurring Radon.

Bulgakova O., Zhabayeva D., Kussainova A., Pulliero A., Izzotti A., and Bersimbaev R.I., (2018). miR-19 in Blood Plasma Reflects Lung Cancer Occurrence but Is Not Specifically Associated with Radon Exposure. Oncology Letters, 15, 88168824.

Chauldhry M.A., (2014). Radiation-Induced MicroRNA: Discovery, Functional Analysis, and Cancer Radiotherapy. Journal of Cellular Biochemistry, 115(3), 436-449.

Cui F.M., Li J.X., Chen Q., Du H.B., Zhang S.Y., and Nie J.H., (2013). RadonInduced Alterations in Micro-RNA Expression Profiles in Transformed BEAS2B Cells. Journal of Toxicology and Environmental Health, Part A, 76(2), 107-119.

Izzotti A., Calin G.A., Steele V.E., Croce C.M., and De Flora S., (2009). Relationships of MicroRNA Expression in Mouse Lung with Age and Exposure to Cigarette Smoke and Light. The FASEB Journal, 23(9), 3243-3250.

Izzotti A., Carozzo S., Pulliero A., Zhabayeva D., Ravett J.L., and Bersimbaev R., (2016). Extracellular MicroRNA in Liquid Biopsy: Applicability in Cancer Diagnosis and Prevention. American Journal of Cancer Research, 6(7), 14611493.

Izzotti A., and Pulliero A., (2014). The Eff ects of Environmental Chemical Carcinogens on The MicroRNA Machinery. International Journal of Hygiene and Environmental Health, 217(6), 601-627.

Kanwal M., Ding X.J., and Cao Y., (2017). Familial Risk for Lung Cancer. Oncology Letters, 13, 535-542.

Kreuzer M., Fenske N., Schnelzer M., and Walsh L., (2015). Lung Cancer Risk at Low Radon Exposure Rates in German Uranium Miners.British Journal of
Cancer, 113, 1367-1369.

Nair N., Kumar S., Gongora E., and Gupta S., (2013). Circulating miRNA as Novel Markersfor Diastolic Dysfunction. Molecular Cellular Biochemistry, 376, 33-40.

Nie J., Wu J., Chen Z., Jiao Y., Zhang J., Tian H., Li J., and Tong J., (2019). Expression Profiles of Long Noncoding RNA in Mouse Lung Tissue Exposed to Radon. Journal of Toxicology and Environmental Health, Part A, 82(15), 854-861.

Pei W., Tao L., Zhang L.W., Zhang S., Cao J., Jiao Y., Tong J., and Nie J., (2017). Circular RNA Profiles in Mouse Lung Tissue Induced by Radon. Environmental Health and Preventive Medicine, 22:36, DOI: 10.1186/s12199017-0627-6.

Reisz J.A., Bansal N., Qian J., Zhao W., and Furdui C.M., (2014). Eff ects of Ionizing Radiation on Biological Molecules-Mechanisms of Damage and Emerging Methods of Detection. Antioxidants and Redox Signaling, 21(2), 260-292.

Rosenberger A., Hung R.J., and Christiani D.C., (2018). Genetic Modifiers of Radon-Induced Lung Cancer Risk: A Genome-Wide Interaction Study in Former Uranium Miners. International Archives of Occupational and Environmental Health, 91, 937-950.

Sosa V., Moliné T., Somoza R., Paciucci R., Kondoh H., and Leonart M.E., (2013). Oxidative Stress and Cancer: An Overview. Ageing Research Reviews, 12(1), 376-390.

United Nations Scientific Committee on the Effects of Atomic Radiation (2000). Sources and Effects of Ionizing Radiation.

Wang Y., Wang L., Chen C., and Chu X., (2018). New Insights into The Regulatory Role of MicroRNA in 
Tumor Angiogenesis and Clinical Implications. Molecular Cancer, 17: 22, DOI: $\quad 10.1186 / \mathrm{s} 12943-018-0766-4$.

World Health Organization (2009).

WHO Handbook on Indoor Radon: a Public Health Perspective. and Luo Z., (2013). miR-194 Suppresses Metastasis of Non-Small Cell Lung Cancer through Regulating Expression of BMP1 and p27kip1. Oncogene, 33, 1506-1514 Wu X., Liu T., Fang O., Leach, L.J., Hu X.,

How to cite this article:

Tirthankar Dalui and Ankita Mondal. 2020. Radon: The Hidden Killer. Int.J.Curr.Microbiol.App.Sci. 9(09): 251-257. doi: https://doi.org/10.20546/ijcmas.2020.909.031 